\title{
THE RING AND BALL METHOD OF TEST FOR SOFTENING POINT OF BITUMINOUS MATERIALS, RESINS, AND SIMILAR SUBSTANCES
}

\author{
By Percy H. Walker
}

\section{ABSTRACT}

The softening point of materials which, like asphalt, have no definite melting point, but which when heated gradually change from brittle or very thick and slow-flowing materials to more mobile liquids, can only be determined by some arbitrary method. The ring and ball method which briefly consists of determining the temperature at which a disk of the material held in a ring and loaded with a ball will flow through a definite distance when heated at a prescribed rate is one of the best methods for such tests. Published directions for making the test are, however, open to very serious objections, and this paper describes the apparatus and procedure used at the National Bureau of Standards. The principal modifications in the apparatus are a beveled instead of a cylindrical ring, and a centering device for the ball. The procedure is so described that some latitude in nonessential details is permitted.

\section{CONTENTS}

I. Introduction

II. Apparatus

1. Ring

2. Ball

3. Container

5. Support for ring and thermometer

III. Preparation of sample

1. Bituminous materials, resins, etc., having softening points $80^{\circ} \mathrm{C}$. or lower. 200

2. Bituminous materials, resins, etc., having softening points higher than $80^{\circ} \mathrm{C}$

V. Typical determinations

\section{INTRODUCTION}

There are many materials which, like asphalt, have no definite melting point, but which when heated gradually change from brittle or very thick and slow-flowing materials to softer or more mobile liquids. For such materials the ring and ball method is a valuable method of test. Briefly, this test is a determination of the temperature at which a disk of the material held in a ring and loaded with a ball will flow through a definite distance when heated at a prescribed rate. However, it is an arbitrary method and in order to get agreeing results a fixed, arbitrary, and closely defined method must be used.

The method is best known to laboratories that test asphalt, and the A. S. T. M. in 1916 adopted a tentative description of the method, amended this and adopted it as standard in 1919, and has since revised it several times, the latest revision being in 1926 under serial designation D36-26. ${ }^{1}$ 
The A.'S. T. M. specifications for this test are open to the following objections:

1. The apparatus as described is not used, nor can it be easily used to meet the rigid requirements given in the text. For example, the ring is supported on one side by a brass wire $1.83 \mathrm{~mm}$ in diameter which is supported in a cork held in a clamp, and this must be placed exactly $2.54 \mathrm{~cm}$ above the bottom of the beaker and 5.08 below the surface of the water.

2. Tolerances are given for inside diameter and thickness of the ring, but not for its depth.

3. The method is limited to asphalts, while if properly described it can be used with numerous materials.

4. The cylindrical ring specified limits its use to materials like asphalt that do not shrink away from the ring. A slightly beveled ring gives with asphalts the same results as the cylindrical ring and has the distinct advantage that it can be used with resins and pitches which may shrink away from the cylindrical ring.

5. The A. S. T. M. method prescribes unessential limitations in the kind and set-up of apparatus, while there is not reason why a number of different forms of apparatus can not be used provided they all comply with certain requirements.

Hence, it seems desirable to describe the apparatus and method as used at the Bureau of Standards.

\section{APPARATUS}

The essential apparatus is as follows:

\section{RING}

A brass ring of the following dimensions:

Depth. $-6.35 \pm 0.10 \mathrm{~mm}$ ( $1 / 4$ inch).

Inside diameter at bottom. $-15.88 \pm 0.10 \mathrm{~mm}(5 / 8 \mathrm{inch})$.

Inside diameter at top. - Not less than inside diameter at bottom nor more than $17.6 \mathrm{~mm}$, preferably $17.46 \mathrm{~mm}$ (11/16 inch).

Outside diameter at bottom. - Not less than $18.0 \mathrm{~mm}$ nor more than $21.0 \mathrm{~mm}$.

Outside diameter at top.-Not less than outside diameter at bottom nor more $21.0 \mathrm{~mm}$.

The interior of the ring may be either tapered, within the tolerances given above, or cylindrical. (The tapered ring is to be preferred, as it can be used with all kinds of materials to which the ring and ball method is applicable. The cylindrical ring, while suitable for asphalts, can not be used with materials that shrink away from the ring, such as resins and pitches.)

The outside of the ring may be either uniformly cylindrical or smaller at the bottom provided the above dimensions are complied with. For convenience in mounting it is advisable to have it smaller at the bottom. (See fig. 1)

\section{BALL}

A steel ball, such as used in ball bearings, $9.53 \mathrm{~mm}(3 / 8$ inch) in diameter weighing between 3.45 and $3.55 \mathrm{~g}$. 


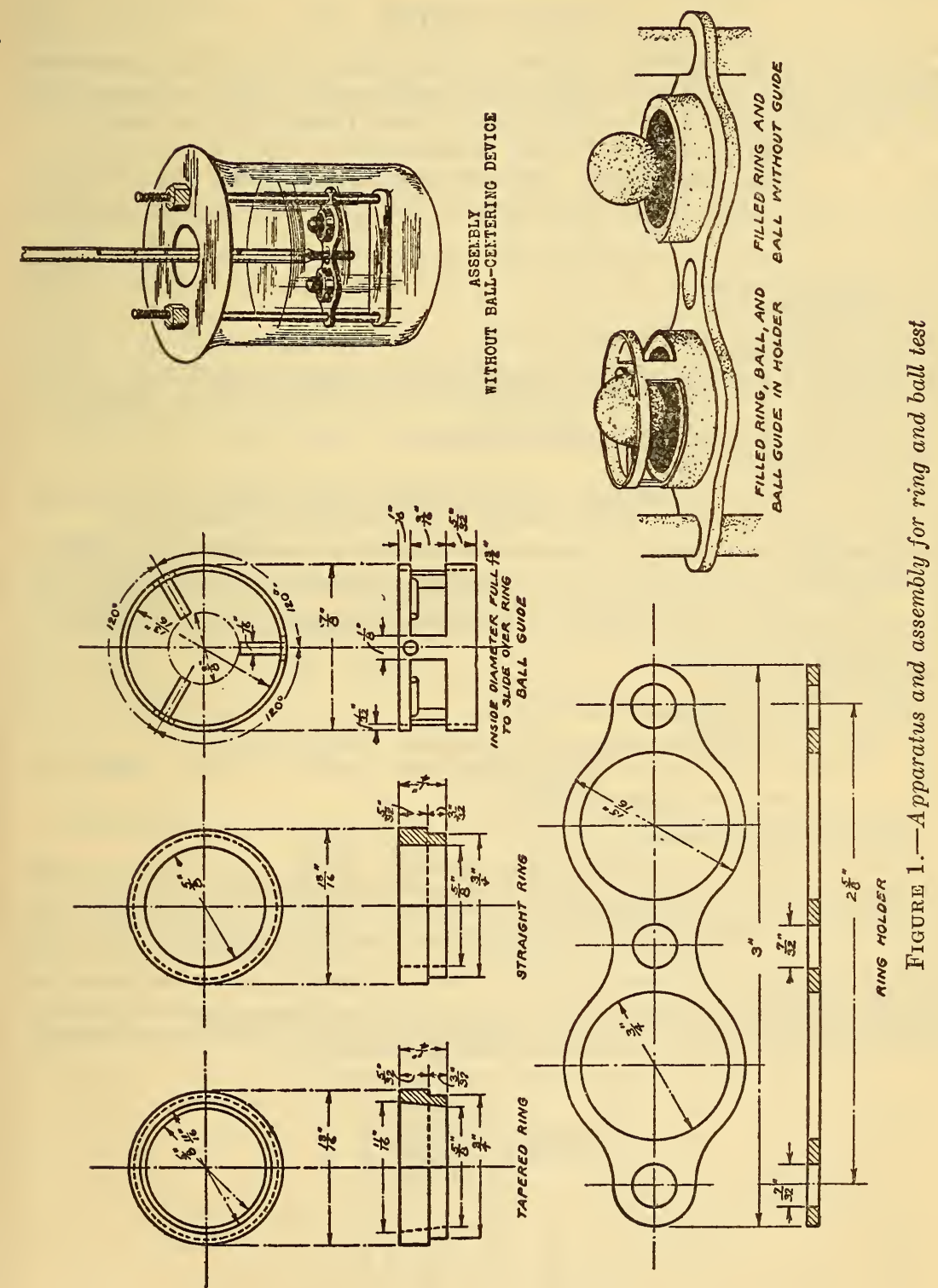




\section{CONTAINER}

A glass vessel, capable of being heated, not less than $8.5 \mathrm{~cm}\left(3 \frac{1}{3}\right.$ inch) in diameter and not less than $10.5 \mathrm{~cm}$ ( $4 \frac{1}{8}$ inches in depth from the bottom of the flare. (A $600 \mathrm{ml}$ beaker, low form.)

\section{THERMOMETER}

For materials having softening points not above $100^{\circ} \mathrm{C}$. a total immersion thermometer meeting the specification given in item 5331 (d) of General Schedule of Supplies, Fiscal Year 1930, is used. ${ }^{2}$

For materials having softening points above $100^{\circ} \mathrm{C}$. and below $300^{\circ}$ C. a partial immersion thermometer meeting the specification given in item 5331 (b) of the General Schedule of Supplies may be used. ${ }^{3}$

2 This specification is as follows:

Type.-Etched stem, glass.

Liquid.-Mercury.

Range and subdivision.-Minus $4^{\circ}$ to $+104^{\circ} \mathrm{C}$. in $0.2^{\circ}$

Total length. -454 to $460 \mathrm{~mm}$.

Stem.-Plain front, enamel back, suitable thermometer tubing. Diameter, 6.0 to $7.0 \mathrm{~mm}$.

Bulb.-Corning normal or equally suitable thermometric glass. Length, 20 to $30 \mathrm{~mm}$. Diameter, not greater than stem.

Distance to $-4^{\circ}$ line from bottom of bulb. -50 to $70 \mathrm{~mm}$.

Distance to $+104^{\circ}$ line from top of thermometer. -20 to $50 \mathrm{~mm}$.

Filling above mercury.-Nitrogen gas.

Top finish.-Glass ring.

Graduation.-All lines, figures, and letters clear cut and distinct. Lines corresponding to even degree marks to be longer than the remaining lines. Graduations to be numbered at each multiple of $2^{\circ}$.

Immersion.-Total.

Scale error.- The error at any point of the scale, when the thermometer is standardized at total immersion, shall not exceed $0.3^{\circ}$.

Special marking. - $\dot{A}$ serial number and the manufacturer's name or trade-mark shall be etched on the stem.

Case.-The thermometer shall be supplied in a suitable case, on which shall appear " $-4^{\circ}$ to $+104^{\circ} \mathrm{C}$. in $0.2^{\circ}$, total immersion."

3 This specification is as follows:

Type.-Etched stem, glass.

Liquid.-Mercury.

Ranges and subdivisions.-Minus 5 to $+300^{\circ} \mathrm{C}$. in $1^{\circ}$.

Total length. -379 to $383 \mathrm{~mm}$.

Stem.-Plain front, enamel back, suitable thermometer tubing. Diameter, 6 co $7 \mathrm{~mm}$.

Bulb.-Corning normal or equally suitable thermometric glass. Length, 10 to $15 \mathrm{~mm}$. Diameter, 5 to $6 \mathrm{~mm}$.

Distance to $0^{\circ}$ line from bottom of bulb. -90 to $100 \mathrm{~mm}$.

Distance to $300^{\circ}$ line from top of stem. -25 to $50 \mathrm{~mm}$.

Filling above mercury. - Nitrogen gas.

Top finish.-Glass ring.

Graduation.-All lines, figures, and letters clear cut and distinct. The first and each succeeding $5^{\circ}$ line to be longer than the remaining lines. Graduations to be numbered at each multiple of $10^{\circ}$.

Immersion. - The words " $76 \mathrm{~mm}$ immersion" and a line around the stem, 75 to $77 \mathrm{~mm}$ above the bottom of the bulb, shall be etched on the thermometer.

Special marking.-A serial number and the manufacturer's name or trade-mark shall be etched on the stem.

Scale error.-The error at any point of the scale, when the thermometer is standardized as provided below, shall not exceed $1^{\circ}$.

Standardization.-The thermometer shall be standardized for $76 \mathrm{~mm}$ immersion and for the following temperatures of the emergent mercury column. These stem temperatures have been chosen as corresponding, on the average, to those likely to occur in the use of the thermometer:

\begin{tabular}{|c|c|}
\hline $\begin{array}{c}\text { Thermom- } \\
\text { eter reading }\end{array}$ & $\begin{array}{c}\text { Average } \\
\text { temperature } \\
\text { of emergent } \\
\text { mercury } \\
\text { column }\end{array}$ \\
\hline$\circ$ & $\circ$ \\
50 & 35 \\
100 & 49 \\
150 & 61 \\
200 & 70 \\
250 & 76 \\
300 & 80 \\
\hline
\end{tabular}

Case.-The thermometer shall be supplied in a suitable case on which shall appear the marking: “- $5^{\circ}$ to $+300^{\circ}$ C., $76 \mathrm{~mm}$ immersion."

The A. S. T. M. partial-immersion thermometer for general use $-5^{\circ}$ to $300^{\circ}$ C., D-183-25 meets this specification. 
The A. S. T. M. low S. P., $-2^{\circ}$ to $+80^{\circ}$ C. thermometer (see A. S. T. M. D-36-26) gives within its range readings identical with the $-4^{\circ}$ to $+104^{\circ}$ C. thermometer specified above. The A. S. T. M. high S. P., $+30^{\circ}$ to $160^{\circ} \mathrm{C}$. thermometer (D-36-26) will read very slightly higher than the $-4^{\circ}$ to $+104^{\circ} \mathrm{C}$. total-immersion thermometer, the difference being less than $0.3^{\circ}$ at $80^{\circ} \mathrm{C}$. and about $0.3^{\circ}$ or $0.4^{\circ}$ at $100^{\circ} \mathrm{C}$. The partial-immersion thermometer gives true temperature readings which as compared with the total-immersion thermometer (used for partial immersion as in this test) will be about $0.6^{\circ}$ to $0.7^{\circ}$ higher at $80^{\circ} \mathrm{C}$. and $1.0^{\circ}$ to $1.1^{\circ}$ higher at $100^{\circ} \mathrm{C}$. . $^{4}$

\section{SUPPORT FOR RING AND THERMOMETER}

Any convenient method for supporting the ring may be used provided it meets the following requirements: The ring must be supported in a substantially horizontal position; the top of the ring must be at least $8 \mathrm{~cm}$ below the top of the container and the bottom of the ring $2.54 \pm 0.02 \mathrm{~cm}$ (1 inch) above a horizontal plate or the bottom of the container; the distance from the center of the ring to thermometer bulb must be not more than $16.5 \mathrm{~mm}$.

A device for centering the ball is desirable, but not essential.

\section{PREPARATION OF SAMPLE}

Melt the sample and stir it thoroughly, avoiding incorporating air bubbles in the mass, and then pour it into the ring so as to leave an excess on cooling. The ring while being filled should rest on a brass plate that has been amalgamated to prevent the sample from adhering to it. After cooling, cut off the excess material cleanly with a slightly heated knife. Determine the softening point within three hours after the sample is prepared.

\section{PROCEDURE}

\section{BITUMINOUS MATERIALS, RESINS, ETC., HAVING SOFTEIING POINTS $80^{\circ}$ C. OR LOWER}

Fill the glass container to a depth of not less than $9 \mathrm{~cm}$ with freshly boiled distilled water that has been cooled to not less than $45^{\circ} \mathrm{C}$. below the softening point of the material under test, provided such softening point is not below $50^{\circ} \mathrm{C}$. If the softening point is below $50^{\circ} \mathrm{C}$. the water shall be cooled to not above $5^{\circ} \mathrm{C}$. Place the filled ring and ball, but not in contact, in the bath and maintain the initial temperature for 15 minutes. Then place the ball in the center of the upper surface of the material in the ring, and at once suspend the support carrying the ring, ball (ball guide if used), and horizontal plate so that the top of the ring is not less than $5.1 \mathrm{~cm}$ below the surface of the water and the $-4.0^{\circ}$ to $+104^{\circ} \mathrm{C}$. thermometer is hanging approximately in the middle of the container. The figure shows details of ring, ball guide, support, container, and assembly of apparatus except tripod and burner. Apply heat in such a man-

4 The use of a total-immersion thermometer for materials of low softening points and of partial-immersion thermometers for materials of higher softening points is recognized as a disadvantage; but the thermometers selected appear to be the best available in their respective ranges, and their use avoids the introduction of new and special thermometers for this work, 
ner that the temperature of the water after the first three minutes of heating is raised uniformly $5.0^{\circ} \pm 0.5^{\circ} \mathrm{C}$. per minute. To facilitate uniform heating, it is advisable to place the burner midway between the center and the edge of the beaker away from the specimen. Report as the softening point the temperature indicated by the thermometer (adding or subtracting any certified corrections, but making no emergent stem corrections) at the instant the sample touches the horizontal plate or the bottom of the container.

\section{BITUMINOUS MATERIALS, RESINS, ETC., HAVING SOFTENING POINTS HIGHER THAN $80^{\circ} \mathrm{C}$.}

Use the same method as given under IV, 1, except that instead of water a suitable bath shall be used, and with materials having softening points above $100^{\circ} \mathrm{C}$. the $-5^{\circ}$ to $300^{\circ} \mathrm{C}$. partial-immersion thermometer shall be used. U. S. P. glycerine is suitable for asphalts and unless otherwise specified shall be used. When the nature of the material tested indicates that glycerine is not suitable, other liquids, air, or inert gases may be used, but in all such cases the kind of bath shall be stated.

Duplicate determinations should agree within less than $1.0^{\circ} \mathrm{C}$. Hence, if the variation is as much as $1.0^{\circ} \mathrm{C}$. a third test should be made.

\section{TYPICAL DETERMINATIONS}

To show the kind of agreement that can be expected with rings of extreme variations of dimensions within the limits of the specifications, two straight and two beveled rings of the following dimensions were selected:

\begin{tabular}{|c|c|c|c|c|}
\hline & \multicolumn{2}{|c|}{ Straight rings } & \multicolumn{2}{|c|}{ Beveled rings } \\
\hline & I & II & III & IV \\
\hline Inside diameter & $\begin{array}{l}m m \\
15.76\end{array}$ & $\begin{array}{l}m m \\
15.93\end{array}$ & $\left\{\begin{array}{l}m m \\
117.22 \\
215.78\end{array}\right.$ & $\begin{array}{l}m m \\
117.40 \\
215.94\end{array}$ \\
\hline 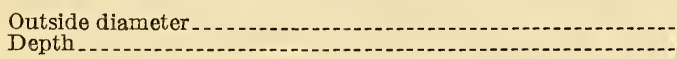 & $\begin{array}{r}21.03 \\
6.45\end{array}$ & $\begin{array}{r}21.05 \\
6.23\end{array}$ & $\begin{array}{r}10.78 \\
21.01 \\
6.46\end{array}$ & $\begin{array}{r}11.04 \\
6.23\end{array}$ \\
\hline
\end{tabular}


Using these rings the following results were obtained on three samples of asphalt:

\begin{tabular}{|c|c|c|c|c|c|}
\hline Asphalt No. & Ring No. & Bath & $\underset{\text { tempera- }}{\text { Initial }}$ & $\begin{array}{l}\text { Rise per } \\
\text { minute }\end{array}$ & $\begin{array}{c}\text { Soften- } \\
\text { ing point }\end{array}$ \\
\hline 1 1 & $\begin{array}{c}\text { I } \\
\text { II } \\
\text { IV }\end{array}$ & Water & $\begin{array}{l}{ }^{\circ} \mathrm{C} . \\
5\end{array}$ & $\begin{array}{l}{ }^{\circ} \mathrm{C} . \\
\quad 5\end{array}$ & $\left\{\begin{array}{r}{ }^{\circ} C . \\
74.0 \\
74.6 \\
74.2 \\
74.0\end{array}\right.$ \\
\hline 2 & $\begin{array}{c}\text { I } \\
\text { III } \\
\text { IV }\end{array}$ & \{ & 5 & 5 & $\begin{array}{l}49.6 \\
49.2 \\
49.0 \\
48.8\end{array}$ \\
\hline $3 \ldots$ & $\left.\begin{array}{c}\text { II } \\
\text { III } \\
\text { IV }\end{array}\right\}$ & & 22 & 5 & $\begin{array}{l}91.0 \\
91.0 \\
90.2 \\
90.0\end{array}$ \\
\hline
\end{tabular}

The writer is indebted to G. W. Clarvoe, jr., for the drawing and suggestions regarding the apparatus and to L. R. Kleinschmidt for the typical determinations.

Washington, August 30, 1929. 